\title{
Trends in the Introductory Communication Course From 1956 to 2016: A Systematic Review of Results From 11 National Survey Studies ${ }^{1}$
}

\author{
Sherwyn P. Morreale $\odot$
}

Keywords: introductory communication course, basic communication course, instructional communication, communication education

\begin{abstract}
Researchers have conducted surveys of the introductory communication course for more than 60 years, starting with two seminal studies in 1956 and 1965, followed by a series of nine replicative studies extending from 1970 to 2016. This systematic review examines the results from those 11 surveys. The results of that review are presented here, including historical trends observed in the thematic categories that indicate how the course has remained consistent or changed during the time period of the surveys. This study concludes with recommendations to inform decision-making about the future of the introductory course, based on the identified historical trends as well as impact factors in the context of higher education today.
\end{abstract}

Over the years, much research has called attention to the importance of communication and communication education. In 2016, a thematic analysis of 679 documents in academic and popular press publications, extending from 2008 to 2015, provided support for the centrality of the communication discipline's content and pedagogy (Morreale, Valenzano, \& Bauer, 2017). In 2019, The Princeton Review compiled a list of the best college majors based on research covering job prospects, alumni salaries, and popularity. Communication(s) was near the top of the list, second only to computer science.

Sherwyn P. Morreale, University of Colorado, Colorado Springs, CO

CONTACT: smorreal@uccs.edu

1. This study is grounded in the committed work of communication education scholars who chose to examine the introductory communication course continuously since 1956, and most recently, Drs. Luke LeFebvre and Leah LeFebvre (2020). The editor and reviewers for the Journal of Communication Pedagogy similarly informed and supported this researcher's efforts to comprehensively review and summarize the results of 11 studies of the communication discipline's "front porch" course. 
Given the importance of communication education, the discipline has a deep commitment to its introductory course, historically referred to as the basic communication course. The term basic course originated as disciplinary shorthand at a time when such a language choice had no particular consequences; however, when communication scholars and administrators now refer to the discipline's foundational or introductory course as basic, that message may suggest to those outside the discipline that the course is rudimentary and not preparing students for more advanced study. Beebe (2013) affirmed that importance, referring to the introductory course as the "front porch" (p. 3) to the communication discipline. Beebe's now-popular metaphor is grounded in the fact that the introductory course is where students, non-communication faculty, and administrators are first welcomed and introduced to the discipline's content and pedagogy. Gehrke (2016) further argued that, as in most disciplines, no other course has as much impact on the communication discipline as does the introductory course.

To ensure that the introductory communication course remains relevant, scholar-teachers must remain committed to continual assessment and modification based on the ever-changing landscape of communication (Anderson et al., 2017; Hess, 2016; Wallace, 2015). To clarify, the introductory course content and pedagogy must align with several contemporary realities. Questions to consider might include: Does the introductory course honor the most critical student learning outcomes for communication, as articulated by particular institutions and/or the student learning outcomes endorsed by the National Communication Association (2019b)? Does the course, substantively and pedagogically, consider mandates identified by employers for incoming employees regarding an array of workplacereadiness communication skills (National Communication Association, 2019a)? Moreover, is the course providing instruction that is perceived as critical to an undergraduate education, considering declining enrollment in higher education (Fain, 2019) and decreasing funding and tight budgets (Knox, 2019)?

Conversations about questions such as these are obviously about positioning the introductory communication course for the future, and that positioning needs to be based on an understanding of how the course has evolved over time. As communication scholars, we believe the introductory course is fundamental to the education of all students, but how are we framing that contribution within our institutions? Knowing the evolution of what has gone before aids in our decision-making and choicemaking about curriculum and pedagogy. Thus, this study summarizes the history and evolution of the introductory communication course via a systematic review of the results of 11 survey studies published between 1956 and 2016.

For more than 60 years, communication researchers have conducted and published a series of national surveys of the introductory communication course, starting with two early seminal studies, by Hargis (1956) and Dedmon and Frandsen (1964). A series of nine replicative studies, extending from 1970 to 2016, focused on the careful examination of the nature and content of the introductory course (Gibson, Gruner, Brooks, \& Petrie, 1970; Gibson, Gruner, Hanna, et al., 1980; Gibson, Hanna, \& Huddleston, 1985; Gibson, Hanna, \& Leichty, 1990; Gibson, Kline, \& Gruner, 1974; Morreale, Hanna, et al., 1999; Morreale, Hugenberg, \& Worley, 2006; Morreale, Myers, et al., 2016; Morreale, Worley, \& Hugenberg, 2010). In essence, each of the 11 surveys serves as a snapshot of the introductory course at a particular moment in time.

To begin, an overview of the history of the 11 survey studies provides background for the present study and a description of several other recent studies focused on the introductory course. Then, the systematic review method used in this study is described, followed by results and conclusions drawn regarding 
trends in the course over time. Finally, recommendations about the future of the introductory course are offered.

\section{Background to the Study}

\section{History of the 11 Surveys of the Introductory Communication Course}

Researchers have been publishing studies about the introductory communication course since the mid-20th century. In 1956, at the behest of the Committee on Problems in Undergraduate Study of the Speech Association of America (SAA, now known as the National Communication Association), Hargis systematically researched and published a study to answer the question, "What is the first course in speech?" (p. 26). Six years later, in 1962, a committee appointed by SAA explored this similar question, "What books and/or articles, films, et cetera should be the materials for undergraduate speech instruction?" (Dedmon \& Frandsen, 1964, p. 32). In 1964, Dedmon and Frandsen conducted another national survey that investigated the content used and the activities taught in the introductory course. Following up on those seminal research efforts, in 1970, the Executive Committee of SAA charged Gibson, Gruner, Brooks, and Petrie with the task of again investigating the introductory course. Those researchers made two important contributions to this body of research. They published the first study that contained descriptive data on the nature of the introductory communication course. In addition, they provided this definition of the introductory course:

that course either required or recommended for a significant number of undergraduates, it is that speech course which the department either has or would recommend as being required for all or most undergraduates if the college administration asked it to name a course so required. (p. 13)

The definition of the course provided by Gibson, Gruner, Brooks, \& Petrie (1970) was used for 15 years before it was updated to:

that course, which provides the fundamental knowledge for all other speech courses. It may be a course which is mainly public speaking, interpersonal, or some other combination of speech communication variables. It teaches the fundamentals of speech communication and is the course which the department has or would recommend as a requirement for all or most undergraduates. (Gibson, Hanna, \& Leichty, 1990, p. 234)

In 1999, the Morreale, Hanna, et al. survey again changed the definition of the course, meaningfully referring to it as a communication course rather than a speech communication course:

that communication course either required or recommended for a significant number of undergraduates: that course which the department has, or would recommend as a requirement for all or most undergraduates. (p. 3)

The Gibson, Gruner, Brooks, \& Petrie (1970) national survey was replicated eight times in a series of published studies that regularly informed scholar-teachers about the status of the course at a particular moment in time (Gibson, Gruner, Brooks, \& Petrie, 1970; Gibson, Gruner, Hanna, et al., 1980; Gibson, Hanna, \& Huddleston, 1985; Gibson, Hanna, \& Leichty, 1990; Gibson, Kline, \& Gruner, 1974; Morreale, 
Hanna, et al., 1999; Morreale, Hugenberg, \& Worley, 2006; Morreale, Myers, et al., 2016; Morreale, Worley, \& Hugenberg, 2010).

Taken as a body of research, the 11 studies provide a useful chronicle of how the introductory course has both remained the same and changed over time. Table 1 lists and provides details about each of the 11 surveys.

\begin{tabular}{|c|c|c|c|}
\hline Label & Author(s) & Title & $N$ \\
\hline Seminal 1 & Hargis (1956) & The first course in speech. & 229 \\
\hline Seminal 2 & Dedmond \& Frandsen (1964) & The "required" first course in speech: A survey. & 406 \\
\hline 1 & $\begin{array}{l}\text { Gibson, Gruner, Brooks, } \\
\text { \& Petrie (1970) }\end{array}$ & $\begin{array}{l}\text { The first course in speech: A survey of U.S. colleges and } \\
\text { universities. }\end{array}$ & 564 \\
\hline 2 & Gibson, Kline, \& Gruner (1974) & $\begin{array}{l}\text { A re-examination of the first course in speech at U.S. colleges } \\
\text { and universities. }\end{array}$ & 554 \\
\hline 3 & $\begin{array}{l}\text { Gibson, Gruner, Hanna, } \\
\text { Smythe, \& Hayes (1980) }\end{array}$ & The basic course in speech at U.S. colleges and universities: III. & 552 \\
\hline 4 & $\begin{array}{l}\text { Gibson, Hanna, \& Huddleston } \\
\text { (1985) }\end{array}$ & The basic course at U.S. colleges and universities: IV. & 552 \\
\hline 5 & Gibson, Hanna, \& Leichty (1990) & The basic speech course at U.S. colleges and universities: V. & 431 \\
\hline 6 & $\begin{array}{l}\text { Morreale, Hanna, Berko, \& } \\
\text { Gibson (1999) }\end{array}$ & $\begin{array}{l}\text { The basic communication course at U.S. colleges and } \\
\text { universities: VI. }\end{array}$ & 292 \\
\hline 7 & $\begin{array}{l}\text { Morreale, Hugenberg, \& Worley } \\
\text { (2006) }\end{array}$ & $\begin{array}{l}\text { The basic communication course at U.S. colleges and } \\
\text { universities in the } 21 \text { st century: Study VII. }\end{array}$ & 306 \\
\hline 8 & $\begin{array}{l}\text { Morreale, Worley, \& Hugenberg } \\
\text { (2010) }\end{array}$ & $\begin{array}{l}\text { The basic communication course at 2- and 4-year U.S. } \\
\text { colleges and universities: Study VIII-The 40th anniversary. }\end{array}$ & 208 \\
\hline 9 & $\begin{array}{l}\text { Morreale, Myers, Backlund, \& } \\
\text { Simonds (2016) }\end{array}$ & $\begin{array}{l}\text { Study IX of the basic communication course at 2- and 4-year } \\
\text { U.S. colleges and universities: A re-examination of our } \\
\text { discipline's "front porch." }\end{array}$ & 188 \\
\hline
\end{tabular}

Note. Sample size decline began in 1999.

Several differences across the 11 studies are worthy of mention. The survey instruments used in the nine replicative studies were modified, to some extent, with each new research effort, to reflect the changing pedagogical concerns and interests of the times. Also, as Table 1 indicates, the sample size of survey respondents tended to vary over time but with a marked decline for the recent studies.

\section{Other Studies of the Introductory Communication Course}

In addition to the 11 survey studies that provide the background for understanding the present study, many other researchers also have provided valuable insights into the nature and development of the introductory communication course. To illustrate, Sellnow and Martin (2010) examined the evolution 
of the introductory communication course, including a description of the various ways the course is taught and directions for the introductory course in the future. Valenzano et al. (2014) traced the history of the introductory course from its classical roots to the present day, when it is frequently a required course in general education; those researchers noted the significant changes to the course that occurred in the late 20th century and discussed ramifications for the course as the discipline moved forward in the 21 st century. Joyce et al. (2019) conducted a synthesis of articles published over the last 13 years in the Basic Communication Course Annual, which, similarly to the present study, identified trends in past content of the journal and offered recommendations for future research about the introductory course. The research method used by Joyce et al. will be referenced again in the description of the method used in the present study.

To contribute to this body of literature, the present study investigated these two research questions:

RQ1: What findings of interest can be observed in the results presented in 11 survey studies of the introductory communication course, conducted from 1956 to 2016, related to the following?

i. Course and school demographics

ii. Course expectations and content

iii. Teaching and instruction

iv. Testing and grading

v. Administration and course coordination

vi. Technology and online learning

vii. Problems in the introductory course

RQ2: Given the findings observed in the 11 survey studies, what historical trends can be identified in each thematic category, and have these trends remained consistent or changed during the time period of the surveys?

\section{Method and Procedure}

\section{Method Overview}

The two research questions were investigated using a systematic review methodology. It is a common misunderstanding that a systematic review and a meta-analysis are the same, and these two terms are often used interchangeably (Hanratty, 2018). A systematic review is a detailed, systematic, and transparent means of gathering, appraising, and synthesizing evidence to answer a study's research questions. By contrast, a meta-analysis is a statistical procedure for combining numerical data from multiple separate studies. In this study, the pre-existing results from the 11 surveys of the introductory communication course are systematically reviewed to provide new insights about the introductory course; however, the data are not analyzed for statistical significance, in part because of the varying ways that questions were asked and answered across the 11 surveys.

\section{Procedure}

A number of authors have provided guidelines for conducting a systematic review, but they generally describe a procedure comparable to the steps used by Joyce et al. (2019) in their synthesis of research 
studies published in the Basic Communication Course Annual. Adapted for this study, those steps include: (1) determine the research articles to review; (2) develop thematic categories for use in reviewing the results presented in the 11 survey studies; (3) review and summarize the results in the 11 survey studies using the thematic categories; and (4) identify findings and trends within each of the thematic categories. A brief explanation of the application of these four steps in this study is now provided, with the addition of a fifth validation step intended to confirm the results of steps one to four.

Regarding step one, nine replicative introductory course surveys, extending from 1970 to 2016, served as the original impetus for the present study. In addition to including those nine articles in the sample, a review of literature pointed to the need to complete the historical picture of introductory course studies by including the two earlier seminal studies (Dedmon \& Frandsen, 1964; Hargis, 1956), which had been commissioned by the leading academic association at that time, the Speech Association of America. In each of the 11 published studies, some references were made to the results of earlier studies, though no summative review of the findings of past studies was presented.

For step two, thematic coding categories were inductively developed. The goal of the development procedure was to fully represent the topics and subtopics explored in the results sections of all 11 survey studies. The researcher, using a procedure similar to constant comparison (Lewis-Beck et al., 2004), began by listing the main headings in the results section of the most recent 2016 survey article. That list of main headings was refined by comparing it to the list of headings in the 2010 survey article, then to the 2006 survey article, and so forth, through and including the first published study's results in 1956. The examination of the main headings across the 11 articles resulted in the development of the seven thematic categories listed in Table 2.

Step three began with a careful reading of the results in the 11 articles to confirm which of the articles addressed each of the seven thematic categories. Not all the categories were discussed in all the studies; for example, items regarding technology were not investigated in either of the first two seminal studies. The researcher assigned the items (questions) from each of the results sections in the 11 survey articles to one of the seven categories. The survey items for each category are presented in Table 2. A color-coded version of Table 2, representing the seven categories and the survey items that appeared in each of the 11 studies, is available from the author on request.

Step four, identifying important findings and trends in each category, began with a careful review of the table indicating the recurrence of survey items to identify trends based on repetition across the survey articles. The researcher returned to the original data in the 11 survey articles and reviewed and summarized the findings regarding each item in each category. A summary of the findings and trends in each category was then developed. Any findings were considered important or of interest if they occurred and were repeated frequently across the studies, such as the survey item about course orientation that was repeatedly identified as public speaking. Important findings were also those that emerged as representative of a time frame, such as the emergence and use of various new technologies in the later survey results. Finally, the summary of findings was reviewed to determine what findings pointed to trends that appeared consistent over time or that appeared to change over time. The procedure in step four involved the reasoned, consistent judgment of the researcher, which was followed by using a second coder/reviewer to validate the initial coding. 
TABLE 2

Seven Thematic Categories and Related Survey Items

Category One: Course and School Demographics

1. Type of introductory course/orientation

2. Total number of students enrolled in course across all sections

3. Number of sections offered

4. Class/section size/cap

5. Composition of enrolled students (freshman, sophomore ...)

6. Course required and in general education

7. Growth rate of course/enrollment trends

8. Type of school and size of school/student body

Category Two: Course Expectations and Content

1. Type of course objectives

2. Theory/practice ratio in course

3. Topics covered/most important topics

4. Number of speeches required/performances

5. Textbook used

6. Other course materials and resources

Category Three: Teaching and Instruction

1. Teaching staff

2. Other departments teaching speech courses

3. Teacher autonomy/standardization and consistency

4. Delivery method, self-contained or lecture/lab

5. Communication labs or centers and communication across-the-curriculum

\section{Category Four: Testing and Grading}

1. Oral vs. written assignments

2. Number of graded assignments

3. Grading responsibility, procedure, and feedback

4. Testing and examinations, test-out, and waiver

5. Credits earned for course completion

\section{Category Five: Administration and Course Coordination}

1. Directing the introductory course

2. Training for teaching assistants and teaching staff

3. Program evaluation and assessment

\section{Category Six: Technology and Online Learning}

1. Technology in the introductory course

2. Distance education and online learning

Category Seven: Problems in the Introductory Course

Step five was added to provide examination of the reasoned consistency of the results of the study's procedures. The coder/reviewer, uninvolved with this study but familiar with the introductory communication course, independently reviewed the development of the thematic categories and the items and findings identified as important for each category. The review by the independent coder/ reviewer confirmed that all the identified thematic categories had been developed with consistency based on a systematic review of the 11 survey articles. The coder/reviewer also read the final description of the results to ensure that they accurately presented the findings. Finally, non-statistical validity was accomplished by the researcher by comparing the categories in this study to those in the other most recent synthesis of research articles about the introductory course, published in the Basic Communication 
Course Annual (Joyce et al., 2019). Except for classroom climate, Joyce et al.s categories are represented in the thematic categories in this study.

\section{Results}

The findings of the systematic review of the 11 studies are presented in response to RQ1. Trends in the findings are discussed in response to RQ2, including commentary about how the course has remained consistent or changed during the time period of the surveys.

\section{Research Question One}

RQ1 asked: What findings of interest can be observed in the results presented in 11 survey studies of the introductory communication course, conducted from 1956 to 2016, related to the following?

i. Course and school demographics

ii. Course expectations and content

iii. Teaching and instruction

iv. Testing and grading

v. Administration and course coordination

vi. Technology and online learning

vii. Problems in the introductory course

To respond to this question, the results of the review are organized based on the seven thematic categories. Findings are reported for most items in a category, some in more detail than others, based on the availability of data in the survey articles. More information about a category or a finding is available by contacting the author directly.

\section{Course and School Demographics}

Category One includes the findings related to eight survey items.

Type of Introductory Course/Orientation. The surveys from 1956 to 2016 (excepting 1974) identified public speaking as the most popular type of introductory course, with the hybrid orientation (interpersonal communication, group communication, and public speaking) second in popularity. Starting in 1970, more than 50\% of responding schools indicated public speaking as their introductory course; in 2016, that percentage rose to $60.8 \%$. The only exception was the 1974 study with public speaking at $21.3 \%$; fundamentals, $12.8 \%$; communication, $24.5 \%$; voice and articulation, $11.3 \%$; multiple, $39.4 \%$. Authors of the 1974 survey (Gibson, Kline, \& Gruner) indicated this deviation could have merely reflected course name change rather than course content, which may have caused ambiguity for respondents answering this item on the survey. To explain, they pointed to $21 \%$ of 1974 respondents requiring one to three speeches in their courses, and $71 \%$ requiring from four to ten speeches, which suggested the course was public speaking.

Total Number of Students Enrolled. Only three of the 11 surveys reported a finding about total enrollment in all sections of their introductory course. The first such report was in 1970, 100-500 total students enrolled, with highest enrollments occurring in universities and lowest in community colleges 
and private liberal arts schools. In 2010, 61\% reported 101-250; in 2016, 58\% said 101-750. The 2016 findings indicated a recent increase in the total number of students in the course, compared to 2010.

Number of Sections Offered. Number of sections was reported in nine surveys, from 1970 to 2016. In general, the number of sections offered ranged from five to 20 with fewer at smaller schools and, not surprisingly, more at larger schools. In the recent surveys, the number of sections offered appeared to have held steady but at the higher end of the range. In 2006, $46 \%$ said 21 or more and $28 \%$ said 30 or more; in 2010, $42 \%$ said 20 or more; in $2016,41 \%$ said 20 or more.

Class/Section Size/Cap. Cap sizes were reported in all but one (2006) of the nine surveys, starting in 1970 through 2016 and indicated a gradual increase in class size. In the 1970 and 1974 surveys, cap sizes ranged from 17-22; in the 1980, 1985, 1990, 1999, and 2006 surveys, the top cap rose to 30; and in 2016, the top cap sizes were reported as 36 in-seat (average) and 17 online blended course (average).

Composition of Enrolled Students (Freshman, Sophomore ... ). Composition was reported in six surveys, starting in 1970 through 2010, with the course mostly populated by freshmen and sophomores. No other data are available regarding composition of the student body in the course.

Course Required and in General Education. In the 1956 survey, 80\% of responding schools said the introductory course was a pre-requisite for advanced work in the discipline. In 1965, 69.8\% of schools not offering the major indicated that all students were required to take the introductory course. In 1970, $40 \%$ of schools said the course was required of all students. In 1974, larger schools required the course more often than smaller schools. In 1980, responding schools said the course was required by some divisions. The introductory course as a requirement was not reported again until 2006 with percentages of respondents who required the introductory course in general education steadily increasing: in 2006, $50.2 \%$; in $2010,60.5 \%$; and in $2016,79.4 \%$.

Course Enrollment Trends. From 1970 to 2016, respondents reported that enrollment trends tended to be parallel with school enrollment, with course growth either increasing or staying the same. Only in 1980 did $31 \%$ of respondents report enrollment in the course increasing faster than school enrollment. Over time, only a small percentage of survey respondents reported any decrease in enrollment. To illustrate, in the most recent survey in 2016, only $9 \%$ of reporting schools indicated that enrollment had decreased.

Type and Size of School. In the first two surveys, 1956 and 1965, respondents reported a wide variety of school types based on regions. In 1974, 1980, and 1985, state, church, and private schools participated. Then, the 1990 survey reported respondents as $65 \%$ state schools, $20 \%$ church, and $12 \%$ private. That pattern continued; in 1999, 64\% state schools; in 2010, 74\% public and state schools. From 1956 to 2016, responding schools varied greatly in size: small, medium, and large.

\section{Course Expectations and Content}

Category Two includes the findings related to six survey items.

Type of Course Objectives. Only a few studies included a question about learning objectives (1956, 1970, and 1980). The 1956 study said respondents reported a varied collection of objectives, such that a categorical table listing the objectives was necessary. Six categories of objectives included general, composition, delivery, adjustment, listening and criticism, and miscellaneous. The 1970 and 1980 
studies did not list the objectives, though the 1980 study indicated that objectives were mostly stated in behavioral terms.

Theory/Practice Ratio in Course. The ratio of theory to practice was asked about in seven of the 11 studies, with all seven indicating the course contained more practice than theory $(1956,1970,1974$, $1980,1985,1990$, and 1999). More than half of respondents indicated that only $30 \%$ of course content was related to theory and $70 \%$ was about performance or some type of presentation.

Topics Covered/Most Important Topics. A query about important topics covered in the course was asked on all but one of the 11 surveys (1974 being the exception). Not surprisingly, since public speaking was identified as the most popular orientation throughout the series of surveys, the popular topics were typically speech performance, composition and delivery, types of speeches, and so forth. Several other topics appeared in the two most recent surveys: in 2010, plagiarism, critical thinking, and research; in 2016, the communication process, ethical communication, and critical thinking.

Number of Required Performances (See also oral vs. written assignments in Category Four). Only four of the 11 surveys inquired about the number of speeches/performances required in the course, with these results: $1974,71 \% 4-10 ; 1985,70 \% 1-3,16 \% 7-10 ; 1990,74 \% 3-6 ; 1999,72 \% 4-6$. Without more recent results, identifying a trend is not useful, except to say the number of required performances tended to vary with course orientation.

Textbook. This query was varyingly asked in all 11 studies, with the early studies asking for the author name and book title of the textbook in use and later studies providing a list of books from which to choose. As a result, the first survey in 1956 reported 48 different books in use and the second survey in 1965 reported 84 books in use, with $43.11 \%$ requiring some edition of five different textbooks. From 1965 to 1985, some iteration of the Alan Monroe public speaking textbook was identified as the number one book used by most respondents (with variations in authorship but always including Monroe). In 1985, a textbook authored by Stephen Lucas appeared as the second most popular book in use; in 1990, that book moved to number one and remained in that position through and including 2016.

Other Course Materials and Resources. Nine of the 11 surveys asked this question (excepting 1956 and 1970). The results generally seemed to indicate that instructors used whatever resources and instructional technology were available at the time. To illustrate: in 1974, first on the list of other materials were handouts, tapes, films, and journals; in 1980, first on the list were handouts, films, models, slides, and transparencies. The use of television for recording and playback was mentioned for the first time in 1985. Starting in 1990 and then in 1999, the use of videotapes and video recording appeared; in 2006, PowerPoint and the World Wide Web, the internet, was added to the list of technologies used in the course. In 2010, video exemplars, case studies, and media and technology were referenced as instructional support resources; in 2016, media and technology were listed again, but also online teaching.

\section{Teaching and Instruction}

Category Three includes the findings related to five survey items.

Teaching Staff. From 1970 to 1980, some decrease in the academic preparation level of those teaching the course was evidenced. In 1970, the introductory course was taught primarily by associate and full professors whereas 29\% of the course instructors in 1980 were associate and full professors. While not all the surveys reported the academic level of the teaching staff, a general trend toward lower ranked 
faculty teaching more of the introductory courses was identified in recent studies. In the 1999 study, instructors most frequently taught the course and GTAs were mentioned less often. In the next study, in 2006, 71\% of responding schools said they used GTAs to teach the course. The 2010 and 2016 studies gathered data separately for 2- and 4-year schools. In both surveys, at both types of schools, part-time adjunct faculty carried the greatest teaching load, followed by instructors at 2-year schools and GTAs at 4-year schools. Relatedly, in the 2016 study, aggregated results from 2- and 4-year schools indicated an MA in Communication was required to teach the introductory course.

Other Departments Teaching Speech Courses. Over time, only a low percentage of respondents indicated competition from other departments teaching communication and/or speech. This question was not included in all the surveys, though available responses indicate these percentages: in 1974, 11\%; in 1980 , fewer than $10 \%$; in $1990,5 \%$; in $1995,14 \%$.

Teacher Autonomy/Standardization and Consistency. In the early years of the series of replicative surveys (1974 to 1990), teacher autonomy was identified as "great," meaning that course instructors had a great deal of autonomy. However, standardization, as reported in the surveys from 1999 to 2016, steadily increased, with a greater percentage of schools favoring more uniformity/standardization across sections. The 2016 survey reported that 2- and 4-year schools approached achieving consistency across sections similarly, rank-ordered as follows: (1) try to meet the same learning objectives (2-year, $89.9 \%$ and 4 -year, $88.6 \%)$; (2) use the same learning objectives, but have autonomy in developing course content and instructional methods (2-year, $83.6 \%$ and 4 -year, $82 \%$ ); (3) teach using the same textbook (2-year, $81 \%$ and 4 -year, $83.2 \%$ ); (4) use the same major assignments (2-year, $73.5 \%$ and 4 -year, $74.9 \%$ ).

Delivery Method, Self-Contained or Lecture/Lab. Throughout the history of the surveys, a standalone (self-contained) classroom delivery method, with one instructor teaching the class, was far more popular than large lectures or a large lecture and recitation model. For example, in the most recent survey in $2016,11.1 \%$ of respondents reported using mass lectures as their primary delivery method, whereas $84 \%$ reported using an individual stand-alone instructional model. Data regarding online delivery of the course is reported in Category Six.

Communication Labs or Centers and Communication Across the Curriculum. None of the surveys asked about communication labs until 1999, and then their use and support of the introductory course was not reported as substantial. That said, the 2010 survey reported twice as many 2-year as 4-year schools were using a center or lab. Also, in 1999, the surveys started asking about communication across the curriculum programs; only $3 \%$ of respondents reported such programs were active on their campuses.

\section{Testing and Grading}

Category Four includes the findings related to five survey items.

Oral vs. Written Assignments. This question was asked in the surveys starting in 1974 through 2016. Across those surveys, the comparative weight of oral and written assignments indicated that instructors placed more emphasis on performance and oral activity by including more of those assignments. For example, respondents to the most recent survey in 2016 reported requiring oral and written assignments, as follows: $38 \%$ required one to three performances and 33.8\% required four performances; $23.8 \%$ required one to three written assignments and $13.2 \%$ required four written assignments (outlines, peer evaluations, papers, self-evaluations). 
Number of Graded Assignments. Most early reports about the total number of graded assignments were variable and not representative of a trend. More recently, in 1999, 71\% of respondents said they require four to six graded assignments, whereas in 2006, 61.3\% reported requiring four to six such assignments. The 2010 and 2016 surveys did not ask about the total number of graded assignments.

Grading Responsibility, Procedure, and Feedback. The surveys from 1970 to 2016, except for 2010, inquired about grading (i.e., who had responsibility for grading and feedback procedures). Speeches were reported as evaluated and graded by the course instructor, who, as already reported, was often a GTA. Students presented to the classroom audience with the instructor providing feedback, though peer feedback was mentioned in some surveys. Some variability was reported regarding whether oral feedback occurred immediately after the presentation or later in written form.

Testing and Examinations, Test-Out, and Waiver. The surveys from 1980 to 2016 inquired about testing and examinations. A majority of respondents reported exams/tests were teacher-generated, not departmental. Throughout the surveys, a question about exemptions or waivers indicated that very few schools allowed them. For the few reporting such an allowance, it was either by performance or a written exam.

Credits Earned for Course Completion. Responses on the surveys over time indicated that a majority of schools were on a semester system and offered the course for three credits.

\section{Administration and Course Coordination}

Category Five includes the findings related to six survey items.

Directing the Introductory Course. Two recent surveys, in 2006 and 2010, asked questions about introductory course directors and how activities in the course are coordinated. More than half of 2- and 4 -year schools reported having a course director $(2006,67 \% ; 2010,71.6 \%)$. In the 2006 survey, the faculty ranks of the course directors were reported as assistant professors (41.3\%), associate professors (37.4), and full professors (21.2\%); in the 2010 survey, faculty ranks were reported as instructors (8\%), assistant professors (10.5\%), associate professors (16.4\%), full professors (23.5\%). Regarding compensation or incentives for serving as introductory course director, the 2010 study reported that $6.9 \%$ received a financial incentive and $19.49 \%$ received a work reduction.

Training for Teaching Assistants and Teaching Staff. All nine replicative studies, from 1970 to 2016, identified varying aspects of the training of course instructors as challenging. For example, training and monitoring instructor performance was identified as a problem in the 1970, 1980, 1985, and 2016 surveys; training GTAs in instructional evaluation procedures in the 1980 survey; equitable evaluation of student performance in the 1974, 1980, and 1985 surveys; and achieving reliable standards in grading in the 1990 survey. Because the questions about training across the surveys varied a great deal, little information about the content and duration of the trainings can be reported. However, two surveys did report that only a minority of introductory course directors are responsible for training instructors $(1999,26.7 \% ; 2010,36.5 \%)$.

Program Evaluation and Assessment. Methods of assessment in the introductory course, as reported in 1999, 2006, 2010, and 2016, tended to reflect the programmatic approaches to assessment popular at the time. In 1999, student feedback from student course surveys was the most popular form of program assessment (74.5\%). In 2006, competency-based assessment gained in popularity (85\%). In 
2010, assessment took a greater foothold, as only $12.7 \%$ of respondents reported no formal assessment process was in place for their introductory course. However, $87.9 \%$ of the 2010 respondents said their assessment process did not satisfy the expectations of those outside the course, on and off campus. In 2010, the assessment results were used, in descending order, to improve course assignments, enhance course content, revise learning objectives, improve instructor training, and improve course delivery.

\section{Technology and Online Learning}

Category Six includes the findings related to two survey items.

Technology in the Introductory Course. The 11 studies did not report extensively about the use of technology until the more recent surveys, except for questions about the use of video replay and recordings. From 1974 to 2006, the surveys reported that most introductory courses used film or video recording of student performances (mostly speeches) for later review by the students. Starting in 1990 and then in 1999, the surveys reported that films and video recordings also were used to enhance instruction in the course. Also starting in the mid-1990s, with the widespread use of presentation software programs, technology assumed a greater presence in the introductory course and in the surveys. PowerPoint, for example, was reported as the most widely taught technology in the introductory course in 2006, 2010, and 2016. Also, in the 2010 survey, video exemplars, case studies, and other media were included on lists of instructional technologies used in the course. In general, the use of technology in the introductory course kept pace with the emerging technological tools available at the time of each survey, but with 2 -year schools slightly ahead of 4-year schools in some ways. In 2010, 2-year schools reported more extensive use of web and web CT than 4-year schools. In 2016, 2-year programs (51.5\%) reported more online delivery of the introductory course than 4-year programs (16.4).

Distance Education and Online Learning. The surveys in 2006, 2010, and 2016 reported the introductory communication course was already being delivered online. At about the same time, concerns became more widespread about teaching communication courses online, particularly the public speaking course (Allen, 2006; Hunt, 2012). Issues about online public speaking instruction $(2006,2010,2016)$ related to how a "real audience" can be achieved, the quality of the student and teacher interactions, and instructor and student competence in the use of online teaching and learning technologies. The surveys also indicated the amount of training for teaching communication online was not as comprehensive and consistent as might be ideal, with 9 hours being the average amount of training time at most 2- and 4-year schools.

\section{Problems in the Introductory Course}

Category Seven summarizes the findings related to only one survey item, but that question was asked across nine of the surveys.

A query about the top problems in the introductory communication course began with the 1970 survey and continued until 2016. Table 3 paints a picture of what constituted key concerns over time for instructors and administrators by listing the 16 greatest problems aggregated across the nine replicative studies, in rank-ordered groups from most problematic to least problematic. For the 17 top problems, subgroups are listed that were the terms or phrases used by survey respondents to identify their top problems. The top three greatest problems, as identified across the nine replicative studies (1970 to 2016), were qualifications of instructors, consistency across sections (standardization), and training of instructors. 


\begin{tabular}{|c|c|}
\hline \multicolumn{2}{|r|}{$\begin{array}{l}\text { TABLE } 3 \\
\text { Top Problems in the Introductory Course, } 1970 \text { to } 2016\end{array}$} \\
\hline & Groups of Problems and Subgroups of Identifying Terms \\
\hline \multirow[t]{3}{*}{1} & Qualifications of Instructors \\
\hline & Staff \\
\hline & Part-Time Faculty \\
\hline 2 & Consistency Across Sections (Standardization) \\
\hline \multirow[t]{2}{*}{3} & Training of Instructors \\
\hline & $\begin{array}{l}\text { Teaching Assistants / Monitoring TA Performance } \\
\text { Equitable Evaluation of Student Performance } \\
\text { Achieving Reliable Standards in Grading } \\
\text { Training GTAs in Instruction/Evaluation Procedures }\end{array}$ \\
\hline \multirow[t]{8}{*}{4} & Course Design \\
\hline & Developing and Maintaining Performance Standards \\
\hline & Time to Cover Course Objectives \\
\hline & Textbook Selection \\
\hline & Selecting Appropriate Test \\
\hline & Determining Course Content and Philosophy \\
\hline & Reconciling Theory vs. Practice in the Classroom \\
\hline & Audience Problems / Listening \\
\hline 5 & Financial Support \\
\hline 6 & Class Size \\
\hline \multirow[t]{8}{*}{7} & Students \\
\hline & Negative, Apathetic Attitudes Toward Required Course \\
\hline & Student Apprehension \\
\hline & Attendance \\
\hline & Student Motivation (Ability vs. Grade) \\
\hline & Students Lacking Basic Communication Skills \\
\hline & Diversity of Student Interests \\
\hline & Heterogeneity Regarding Speech Ability and Background \\
\hline 8 & General Administration \\
\hline 9 & Evaluation of Instructors \\
\hline 10 & Technology Issues \\
\hline 11 & Assessment of Student Learning \\
\hline 12 & Grade Inflation \\
\hline 13 & Lack of Equipment and Facilities \\
\hline 14 & Classroom Civility \\
\hline \multirow[t]{3}{*}{15} & Attitudes \\
\hline & Administration Support/Attitudes Toward Course \\
\hline & Faculty Attitude \\
\hline 16 & Challenging Students to Achieve High Performance Levels \\
\hline 17 & Support for Other Departments/Over Demand for Course \\
\hline
\end{tabular}


Table 4 presents the three top problems identified by the respondents in each survey, from 1970 to 2016. The top problems, as identified individually in each of the nine surveys, provide more insight about the ebb and flow of the concerns and problems over time. For example, the concern about qualified instructional staff first appeared in 1980 and then continued to be mentioned in every survey, through and including 2016. Consistency of course content also first appeared in 1980 and was mentioned again in 1990, 1999, 2006, and 2010, but not in 2016. Class size, as a top problem, was mentioned in 1974, 1980,1985 , and 1990 .

\begin{tabular}{|c|c|c|c|}
\hline Survey Year & Top Problem & Problem Two & Problem Three \\
\hline 1970 & Additional faculty & Classroom space & Administrative support \\
\hline 1974 & Lack of time & Class too large & Textbook selection \\
\hline 1980 & Class size & Consistency of course content & Acquiring qualified staff \\
\hline 1985 & Class size & Time to cover course content & Acquiring qualified staff \\
\hline 1990 & Class size & $\begin{array}{l}\text { Quality and consistency of } \\
\text { instruction }\end{array}$ & $\begin{array}{l}\text { Finding and retaining quality } \\
\text { part-time instructors }\end{array}$ \\
\hline 1999 & Maintaining consistency & $\begin{array}{l}\text { Finding, training, and } \\
\text { maintaining faculty }\end{array}$ & Fighting faculty burnout \\
\hline 2006 & Consistency & Part-time faculty & Students \\
\hline 2010 & Consistency across sections & Qualifications of instructors & Technology issues \\
\hline 2016 & Financial support & Qualifications of instructors & Evaluation of instructors \\
\hline
\end{tabular}

\section{Research Question Two}

RQ2 asked: Given the findings observed in the 11 survey studies, what historical trends can be identified in each thematic category, and have these trends remained consistent or changed during the time period of the surveys? The following responses to this question focus on trends observed in the findings presented for each of the seven categories.

\section{Trends in Course and School Demographics}

One finding that has remained the same from 1956 to 2016 (excepting 1974) is the steadfast identification of public speaking as the dominant orientation of the introductory course. This commitment to public speaking could suggest an adherence to the roots of communication as a discipline and its role in the original disciplinary associations. Another explanation may relate to the desire of communication chairs and course directors to respond favorably to other faculty and administrators' interests in improving students' basic presentation skills. Yet another reason may be a tendency to do what the department has always done, teach public speaking, rather than considering mandates from the general public and from employers for the inclusion of a more varied set of workplace-related communication skills in the introductory course.

Another trend of interest in this category is the steady increase in enrollment in the introductory course, a change that has paralleled an increase in school enrollment. The increase in enrollment in the course appears to have been managed by increasing the number of sections and number of students in the 
sections. That said, a similar increase in the presence of the introductory course in general education $(2006 ; 2010 ; 2016)$ is a matter that potentially could require an increase in support for the course and perhaps the department. Ascertaining the disciplinary composition of students enrolled in the course, communication or non-communication, could provide some evidence of the need for more support.

\section{Trends in Course Expectations and Content}

Most of the results reported for this category are what might be expected by anyone familiar with the introductory course, although several trends and linkages can be observed. For example, the 1980 survey indicated learning objectives were stated mostly in behavioral terms, although cognitive and affective objectives also are important to communication competence (Spitzberg, 1983). The ongoing results reporting a greater focus on performance over theory coincide with the focus on behavioral objectives for the course and the popularity of the skills-focused public speaking course orientation, perhaps to the neglect of cognitive and affective learning.

Also, the popularity of the Stephen Lucas textbook since 1990 suggests a need for instructors' awareness of the extent to which textbooks may shape or focus content in the introductory course. Principles of instructional design call for first developing learning objectives and then determining pedagogical strategies and resources, such as a textbook, which specifically help accomplish the course objectives. Finally, on a positive note, the findings in this category indicate that introductory course instructors do tend to keep pace with and make use of the latest instructional resources, such as technology tools.

\section{Trends in Teaching and Instruction}

The nexus of two findings in this category is noteworthy. Perhaps the most important finding about teaching and instruction relates to the changing trend toward lower-ranked faculty teaching most introductory communication courses. At the same time, the delivery method of the course remained the same through 2016 - the individual, stand-alone classroom. The use of lower-ranked teachers (adjuncts, GTAs, and instructors) teaching the course, in the privacy of the stand-alone classroom, may be linked to the identified need for greater standardization to achieve consistency of content and instruction. Additionally, the decrease over time in teacher autonomy and the increase in a concern for consistency across multiple sections has become a critical quality control issue for the introductory course. Administrators, department chairs, and introductory course directors may need to consider addressing the quality of introductory course instruction, for example, by elevating instructors' academic level and providing adequate instructor training.

\section{Trends in Testing and Grading}

The trend in this category toward more oral than written assignments aligns with other findings about public speaking as the most popular course orientation and course content that is skills-focused and emphasizes performance over theory. The trend toward GTAs as the primary instructors at 4-year schools highlights a concern that evaluating and grading speeches and performances is now primarily the responsibility of GTAs who are transients in the job. Department chairs and introductory course directors need to continue to pay attention to matters like inter-rater reliability training for those evaluating and providing feedback about students' speeches in the course. 


\section{Trends in Administration and Course Coordination}

Of some interest in this category's findings is the indication that more than half of reporting 2-and 4-year schools have an introductory course director. That said, considering the responsibilities associated with directing the course and the importance of the course itself, two concerns are worth noting. The lack of financial remuneration or any other form of compensation for the director is problematic, as is the finding that most course directors are not providing the training for instructors.

Regarding assessment in the introductory course, those processes appear to have matured concomitantly with the maturation of the assessment movement itself, with increasing numbers of responding schools indicating assessment procedures are in place. However, a need exists to better understand why assessment of student learning in the course has failed to satisfy the expectations of those outside the course, on and off campus, as indicated by a majority of 2010 survey respondents.

\section{Trends in Technology and Online Learning}

The surveys indicated that introductory course pedagogy has changed and kept pace with the latest emerging instructional technology over the years. However, within the discipline, some debate has surrounded using the latest technology to teach the dominant course orientation, public speaking. Proponents of teaching any introductory communication course online suggest there are always new challenges to disciplinary pedagogy, and the new technologies simply reflect changes in how people communicate in the 21st century. Opponents often suggest that teaching communication courses online is a result of administrators seeking a financial advantage, saving on the bricks-and-mortar of in-seat teaching, without enough concern for instructional integrity. While this debate is not over, the responsibility of introductory course directors and instructors is to ensure that courses offered online are as substantively and pedagogically rich as their in-seat courses (Morreale, Thorpe, \& Ward, 2019). An interesting aside is the finding that 2-year schools are embracing online delivery of the introductory course more than 4-year schools. Instructors and administrators at both types of schools may need to ponder this finding, since any delivery method has some advantages and some disadvantages.

\section{Trends in Problems in the Introductory Course}

The rank-ordered top problems identified in this category bear witness to the old expression-the more that we change, the more we remain the same. Over the course of the surveys, the most critical concerns repeatedly related to who is teaching the course, how well the instructors are trained, and the consistency of instruction across multiple sections. Obviously, those concerns are intertwined. The concern regarding who teaches the course appears to have been about locating, training, and retaining a well-qualified instructional staff. It follows that a well-qualified staff would favorably impact how well the course is taught and whether consistency across multiple sections is achieved. Class size, which was also identified as a top problem in four of the surveys (1974, 1980, 1985, and 1990), is a related concern. The increase in the number of students in sections of the course could affect whether qualified faculty can be retained and how well the course is taught.

\section{Conclusions and Recommendations}

In addition to the specific observations just provided about each thematic category, other conclusions and recommendations about the future of the introductory course, more general in scope, are worth 
consideration. As suggested in the introduction, this study's results could inform conversations about the course based on: (1) looking back at any historical trends; (2) examining the larger context in higher education that may impact the introductory course; and (3) looking forward for opportunities for innovative approaches for strengthening and advancing the course beyond its current configurations.

As a case in point, the historic trend that indicates an ongoing commitment to public speaking as the primary orientation for the introductory course may need to be reconsidered. The public speaking course could and should remain a staple in any department's portfolio of course offerings, but perhaps an introductory or foundations course might better serve as the discipline's first course. For the benefit of the campus, such an introductory course could provide an overview of the discipline as it manifests in the department, and it could include disciplinary content that would help all undergraduates achieve the communication learning outcomes articulated by the college or university itself. Such a course also could and perhaps should respond to the communication needs identified as important for graduates entering the contemporary workplace. Recent reports indicate employers are clamoring for employees with communication skills, other than just public speaking (Bauer-Wolf, 2019). A miscellanea of communication skills, conflict management, change management, and storytelling are among the top 10 skills required for the future, according to a recent national analysis of employers (Gaskell, 2019). Relatedly, some consideration should be given to more appropriate labeling of the course, abandoning the term, basic communication course, in favor of a label that better reflects any redesign of the course content.

In examining the larger context in which higher education now finds itself, two external factors call attention to a possible need to re-envision introductory or foundations course for the benefit of the department and discipline. College enrollment in the U.S. has decreased for the eighth consecutive year (Fain, 2019). This year, the overall decline was 1.7 percent, or roughly 300,000 students. Concomitant with the enrollment decline, another recent study reported on the damage to higher education of state disinvestment in public colleges and universities (Knox, 2019). This report concluded that less funding for higher education institutions will negatively affect students, research efforts, and even state work forces. Summarily, in times of decreasing enrollment and deep budget cuts, college and university administrators may need to make difficult decisions about the extent to which they support various programs and courses. Those courses that are attracting students, teaching critical knowledge and skills needed in today's job market, and supporting the institution's mission for student learning will garner more favorable administrative support. Hess (2016) sees these external factors in a positive light. "Communication has encountered a tremendous opportunity-the chance to become an 'essential discipline' in the academy, one like Math or English, which universities consider indispensable to the work they do" (p. 11). Hess further argued that the introductory course is critical to establishing the necessity of the communication discipline, as employers and university administrators see the value of a well-designed and delivered oral communication course, particularly the introductory course.

Over recent years, other notable scholar-teachers have explored opportunities for redesigning the introductory course. In 2015, Wallace described a model for developing a sustainable basic course in communication. Wallace noted that, "... the concept of outcome-driven courses presents both a change from traditional perspectives of the basic communication course as well as an opportunity to integrate communication content into a student's broader college education" (p. 79). Wallace identified four keys to sustainable communication courses in general education: careful development, integration, rigorous assessment, and adaptability. In 2017, Anderson et al. described their applied approach to re-evaluating 
and redesigning their introductory course. Like Wallace, with a concern for consistency of learning outcomes, these scholar-teachers collected participative data and conducted a series of three qualitative surveys that focused on student perceptions of the course. Through collaboration with faculty from across the campus, they explored how the introductory course, in this case public speaking, could take advantage of course redesign efforts, in order to develop an identity for the course and evaluate learning outcomes using student voices.

Also looking to the future, other opportunities for advancing the introductory course abound. For example, instructors in the introductory communication course are well prepared to engage in newer models of course delivery, such as online or hybrid instruction of the course. Their background in the knowledge and skills associated with communication education and instructional communication will give them an edge that instructors in other disciplines may not have. Their ability to adapt, instructionally and technologically, to this new normal in higher education will help the introductory course remain far more relevant, as it responds to internal and external realities (Morreale, Thorpe, \& Ward, 2019).

On yet another front, others have offered recommendations about the best path forward for a research agenda for the introductory course. Joyce et al. (2019) called for further research about the course concentrating on diverse student populations, innovative pedagogical methods including online education, and a greater focus on issues specifically related to the introductory course, rather than to instructional communication generally. For example, the list of top problems in the introductory course, identified in this present study, suggests a need to explore, at a minimum, the top three problems.

The trends reported in this study were carefully derived from the systematic review of the responses of many survey respondents, as reported by the authors of the 11 survey articles. Building on those trends and voices from the past, the introductory communication course survey series will continue in the future, perhaps modified to include new questions about positioning the course propitiously for the future. The voices from the past, of colleagues equally committed to the communication discipline's "front porch" course, will continue to be heard well into the future.

\section{References}

Allen, T. H. (2006). Is the rush to provide on-line instruction setting our students up for failure? Communication Education, 55(1), 122-126. https://doi.org/10.1080/03634520500343418

Anderson, L. B., McCloskey, T., Scott, D., Alt, R., \& Gardner E. E. (2017). Redesigning the basic communication course: A case study. Journal of the Association for Communication Administration, 36(2), 36-50. https://web.archive.org/web/20200523052135/https://static1.squarespace.com/static/ 58dbe18c03596e2e942115e9/t/5be0878e4d7a9c6daef85f14/1541441426779/JACA+36-2.pdf

Bauer-Wolf, J. (2019, January 17). Survey: Employers want 'soft skills' from graduates. Inside Higher Education. https://www.insidehighered.com/quicktakes/2019/01/17/survey-employers-want-soft-skillsgraduates

Beebe, S. (2013). Message from the president: “Our front porch.” Spectra, 49(2), 3-22. https://web. archive.org/web/20200617142515/https://www.natcom.org/publications/spectra/may-2013? Userld=36e6252d-896e-41e2-b4cb-dc2fc399f6a2\&sso=d9899d41-731d-45d5-a4c9-222ae71c19c2+

Dedmon, D. N., \& Frandsen, K. D. (1964). The required first course in speech: A survey. The Speech Teacher, 14, 33-37. https://doi.org/10.1080/03634526409377336 
Fain, P. (2019, May 30). College enrollment declines continue. Inside Higher Education. https://web. archive.org/web/20200526185751/https://www.insidehighered.com/quicktakes/2019/05/30/collegeenrollment-declines-continue

Gaskell, A. (2019, February 22). What are the top ten soft skills for the future of work? Forbes. https:// web.archive.org/web/20200521215028/https://www.forbes.com/sites/adigaskell/2019/02/22/what-arethe-top-10-soft-skills-for-the-future-of-work/

Gehrke, P. J. (2016). Introduction to special issue on teaching first-year communication courses. Review of Communication, 16, 109-113. https://doi.org/10.1080/15358593.2016.1193943

Gibson, J. W., Gruner, C. R., Brooks, W. D., \& Petrie, C. R., Jr. (1970). The first course in speech: A survey of U.S. colleges and universities. The Speech Teacher, 19, 13-20. https://doi.org/10.1080/036345270 09377786

Gibson, J. W., Gruner, C. R., Hanna, M. S., Smythe, M. J., \& Hayes, M. T. (1980). The basic course in speech at U.S. colleges and universities: III. Communication Education, 29, 1-9. https://doi. org/10.1080/03634528009378387

Gibson, J. W., Hanna, M. S., \& Huddleston, B. M. (1985). The basic course at U.S. colleges and universities: V. Communication Education, 34, 281-291. https://doi.org/10.1080/03634528509378620

Gibson, J. W., Hanna, M. S., \& Leichty, G. (1990). The basic speech course at U.S. colleges and universities: IV. Basic Communication Course Annual, 2(1), 233-257. https://ecommons.udayton.edu/bcca/ vol2/iss1/16/

Gibson, J. W., Kline, J. A., \& Gruner, C. R. (1974). A re-examination of the first course in speech at U.S. colleges and universities. The Speech Teacher, 23, 206-214. https://doi.org/10.1080/03634527409378089

Hanratty, J. (2018, February 12). What is the difference between a systematic review and a meta-analysis? Meta-Evidence, Campbell Collaboration. http://meta-evidence.co.uk/difference-systematicreview-meta-analysis/

Hargis, D. (1956). The first course in speech. The Speech Teacher, 5, 26-33. https://doi. org/10.1080/03634525609376775

Hess, J. A. (2016). Strengthening the introductory communication course: An opportunity through better alignment with today's needs. Basic Communication Course Annual, 28, 11-21. https:// ecommons.udayton.edu/bcca/vol28/iss1/7/

Hunt, A. W., III. (2012). Why I am not going to teach public speaking online. Explorations in Media Ecology, 11(2), 163. https://doi.org/10.1386/eme.11.2.163_1

Joyce, J., Kritselis, A., Dunn, S., Simonds, C., \& Lynn, B. (2019). Synthesizing the current state of the Basic Communication Course Annual: Furthering the research of effective pedagogy. Basic Communication Course Annual, 31, Article 5. https://ecommons.udayton.edu/bcca/vol31/iss1/5/

Knox, L. (2019, June 18). These cuts have real consequences: A new study surveys the damage of state disinvestment in public universities. Chronicle of Higher Education. https://web.archive.org/ web/20190629063801/https://www.chronicle.com/article/These-Cuts-Have-Real/246516

LeFebvre, L. \& LeFebvre, L. E. (2020). The introductory communication course from 1956 to 2016: A meta-synthesis, Communication Education, 69(2), 199-223. https://doi.org/10.1080/03634523.2019.1 679380

Lewis-Beck, M. S., Bryman, A., \& Liao, T. F. (2004). Constant comparison. In The SAGE encyclopedia of social science research methods. SAGE. https://dx.doi.org/10.4135/9781412950589.n161

Morreale, S. P., Hanna, M. S., Berko, R. M., \& Gibson, J. W. (1999). The basic communication course in U.S. colleges and universities: VI. Basic Communication Course Annual, 11, 1-36. http://ecommons. udayton.edu/bcca/vol11/iss $1 / 5$ 
Morreale, S. P., Hugenberg, L., \& Worley, D. (2006). The basic communication course at U.S. colleges and universities in the 21st century: Study VII. Communication Education, 55, 415-437. https://doi. org/10.1080/03634520600879162

Morreale, S. P., Myers, S. A., Backlund, P. M., \& Simonds, C. J. (2016). Study IX of the basic communication course at two- and four-year U.S. colleges and universities: A re-examination of our discipline's "front porch." Communication Education, 65, 338-355. https://doi.org/10.1080/03634523.2015.10733 39

Morreale, S. P., Thorpe, J., \& Ward, S. (2019). Teaching public speaking online-not a problem but an opportunity. Journal of Communication Pedagogy. https://doi.org/10.31446/JCP.2019.15

Morreale, S. P., Valenzano, J. M., \& Bauer, J. A. (2017). Why communication education is important: A third study on the centrality of the discipline's content and pedagogy. Communication Education, 66, 402-422. https://doi.org/10.1080/03634523.2016.1265136

Morreale, S. P., Worley, D. W., \& Hugenberg, B. (2010). The basic communication course at two- and four-year U.S. colleges and universities: Study VIII-The 40th anniversary. Communication Education, 59, 405-430. https://doi.org/10.1080/03634521003637124

National Communication Association. (2019a). College graduates with communication degrees have the knowledge and skills employers need. https://www.natcom.org/sites/default/files/publications/LOC_4_ College_Graduates_with_Communication_Degrees_Have.pdf

National Communication Association. (2019b). NCA's learning outcomes in communication. https://web. archive.org/web/20200529163350/https://www.natcom.org/learning-outcomes-communication

Sellnow, D. D., \& Martin, J. M. (2010). The basic course in communication: Where do we go from here? In D. L. Fassett \& J. T. Warren (Eds.), The SAGE handbook of communication and instruction (pp. 33-53). SAGE.

Spitzberg, B. H. (1983). Communication competence as knowledge, skill, and impression. Communication Education, 32(3), 323-329. https://doi.org/10.1080/03634528309378550

The Princeton Review. (2019). Top 10 college majors. https://web.archive.org/web/20200426220402/ https://www.princetonreview.com/college-advice/top-ten-college-majors

Valenzano J. M., Wallace, S. P., \& Morreale, S. P. (2014). Consistency and change: The (r)evolution of the basic communication course. Communication Education, 100th Anniversary Issue, 63(4), 355-365. https://doi.org/10.1080/03634523.2014.911928

Wallace, S. P. (2015). A model for the development of a sustainable basic course in communication. Basic Communication Course Annual, 27, 78-101. https://ecommons.udayton.edu/cgi/viewcontent. cgi?article $=1498 \&$ context $=$ bcca 